\section{Commentary: Robotic surgical aortic valve replacement: An evolving option}

\author{
Caroline M. Komlo, BS, and \\ T. Sloane Guy, MD, MBA
}

This report by Badhwar and colleagues ${ }^{1}$ describes the successful operative technique and early results of robotic aortic valve replacement (rAVR) in 20 patients using conventional prostheses via a unique lateral approach. We congratulate the authors for this important contribution that advances the application of the robotic platform for aortic valve replacement (AVR). To date, reports describing rAVR are limited to isolated, single-digit case series via primarily an anterior-medial approach using primarily sutureless valves. ${ }^{2-5}$ This technique is unique because the approach is lateral rather than medial and it summarizes a large and growing experience compared with reports that have been largely case reports or small case series.

We want to amplify several distinct advantages offered by the novel technique described, ${ }^{1}$ which adapts the lateral "mini"-thoracotomy or "working port" incision used by many in robotic mitral valve surgery to rAVR. First, this approach spares the pectoralis major, latissimus dorsi, and right internal mammary artery; minimizes the size of the working port incision; and increases working space compared with conventional anteromedial approaches. It can reduce or eliminate the need for rib-spreading. Thus, patients may benefit from the enhanced recovery that has been demonstrated by the use of this approach in robotic mitral valve surgery. ${ }^{6}$ Totally endoscopic techniques without a thoracotomy are feasible and done by a few

From the Division of Cardiac Surgery, Department of Surgery, Thomas Jefferson University Hospital, Philadelphia, Pa.

Disclosures: T.S.G. reported consultant, proctor, and case observation surgeon for Intuitive Surgical; consultant to Johnson \& Johnson for Robotic Cardiac Surgery; Edwards Lifesciences, consultant and MAB member. C.M.K. reported no conflicts of interest.

The Journal policy requires editors and reviewers to disclose conflicts of interest and to decline handling or reviewing manuscripts for which they may have a conflict of interest. The editors and reviewers of this article have no conflicts of interest.

Received for publication Nov 23, 2020; revisions received Nov 23, 2020; accepted for publication Nov 24, 2020; available ahead of print Dec 3, 2020.

Address for reprints: T. Sloane Guy, MD, MBA, Division of Cardiac Surgery, Department of Surgery, Thomas Jefferson University Hospital, Philadelphia, PA 19107 (E-mail: sloane.guy@jefferson.edu).

J Thorac Cardiovasc Surg 2021;161:1762-3

$0022-5223 / \$ 36.00$

Copyright (c) 2020 by The American Association for Thoracic Surgery

http://dx.doi.org/10.1016/j.jtcvs.2020.11.118

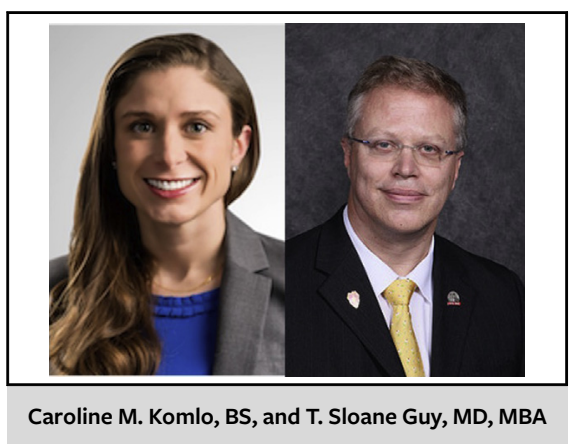

CENTRAL MESSAGE

Robotic aortic valve replacement

(rAVR) through the lateral

approach is a promising new

minimally invasive technique in

our surgical armamentarium for

aortic valve replacement.

centers for mitral valve surgery, including ours, and we feel that rAVR will also benefit from this approach and provide additional advantages over a nonrobotic minithoracotomy approach to AVR.

Second, this series used a variety of conventional prostheses tailored to patient-specific needs. Thus, rAVR offers patients a distinct advantage over current minimally invasive AVR techniques and transcatheter aortic valve replacement (TAVR), which are limited to a narrow scope of valves that lack long-term durability data. This benefit must be appreciated by both surgeons and patients in consideration of the nonsternotomy approaches available for aortic valve surgery, particularly given concern among surgeons related to TAVR for the low-risk patient population. Also, there are patients for whom a TAVR tissue valve is not ideal, such as those with complex bicuspid aortic valves or those who need a mechanical prosthesis. Thus, rAVR may have advantages over TAVR for certain patient populations.

At present, $14 \%$ of all mitral valve repair operations are performed robotically ${ }^{7}$ via the same lateral approach described by the authors in this report. This familiar approach may abbreviate the learning curve for these robotic mitral valve surgeons, making earlier adoption of rAVR more feasible. The opportunity to learn to apply the robotic platform for mitral and aortic valve surgery via the similar approach may motivate cardiac surgeons to invest the time, energy, and resources required to develop the complex skills needed for robotic techniques. Ultimately, the relatively few high-volume robotic cardiac 
surgeons may also limit the adoption of this technique at the current time.

The authors state that the most challenging technical segment of rAVR was the aortotomy closure. There are certainly solutions to this problem, but it is clear this is an important consideration in performing this procedure. Although not reported in this paper, challenges related to inadequate robotic instrumentation necessary for debridement of heavily calcified leaflets ${ }^{3,4}$ have been described. The authors found that this potential concern was not a significant problem.

Innovation is critical to the evolution of our specialty. As noted in Joseph Bavaria's 2017 Presidential Address to the Society of Thoracic Surgeons, the cardiac surgical community cannot shirk its responsibility to continually advance practice with new devices, approaches, and indications for treatment. ${ }^{8}$ The authors are to be commended for their ingenuity and the ability to bring rAVR to patients.

\section{References}

1. Badhwar V, Wei L, Cook CC, Hayanga JA, Daggubati R, Sengupta PP, et al Robotic aortic valve replacement. J Thorac Cardiovasc Surg. 2021;161:1753-9.

2. Folliguet TA, Vanhuyse F, Konstantinos Z, Laborde F. Early experience with robotic aortic valve replacement. Eur J Cardiothorac Surg. 2005;28:172-3.

3. Nagaoka E, Gelinas J, Vola M, Kiaii B. Early clinical experiences of robotic assis ted aortic valve replacement for aortic valve stenosis with sutureless aortic valve. Innovations. 2020;15:88-92.

4. Balkhy HH, Kitahara H. First human totally endoscopic robotic-assisted sutureless aortic valve replacement. Ann Thorac Surg. 2020;109:e9-11.

5. Vola M, Fuzellier J-F, Campisi S, Faure M, Bouchet JB, Sandri F, et al. Totally endoscopic aortic valve replacement (TEAVR). Ann Cardiothorac Surg. 2015;4: 196-7

6. Gammie JS, Zhao Y, Peterson ED, O'Brien SM, Rankin JS, Griffith BP. Lessinvasive mitral valve operations: trends and outcomes from the Society of Thoracic Surgeons Adult Cardiac Surgery database. Ann Thorac Surg. 2010; 90:1401-10.e1

7. Gammie JS, Chikwe J, Badhwar V, Thibault DP, Vemulapalli S, Thourani VH, et al. Isolated mitral valve surgery: the Society of Thoracic Surgeons Adult Cardiac Surgery database analysis. Ann Thorac Surg. 2018; 106:716-27.

8. Bavaria JE. Quality and innovation in cardiothoracic surgery: colliding imperatives? Ann Thorac Surg. 2018;106:1276-82.
See Article page 1753 .

\section{Commentary: Robotic aortic valve replacement-fad or future?}

\author{
J. James Edelman, MD, PhD, ${ }^{\mathrm{a}}$ and \\ Vinod H. Thourani, $\mathrm{MD}^{\mathrm{b}}$
}

In this issue of the Journal, Badhwar and colleagues ${ }^{1}$ report their initial experience with robotic aortic valve replacement. Twenty patients underwent surgical aortic valve replacement (SAVR) using a lateral thoracotomy approach, similar to that used for robotic mitral valve surgery. On cardiopulmonary bypass (CPB) and using aortic crossclamping (XC), calcified valve leaflets were resected and a stented bioprosthesis or mechanical valves were secured

\footnotetext{
From the a Department of Cardiothoracic Surgery and Transplantation, Fiona Stanley Hospital, University of Western Australia, Perth, Australia; and ${ }^{\mathrm{b}}$ Department of Cardiovascular Surgery, Marcus Valve Center, Piedmont Heart Institute, Atlanta, Ga. Disclosures: The authors reported no conflicts of interest.

The Journal policy requires editors and reviewers to disclose conflicts of interest and to decline handling or reviewing manuscripts for which they may have a conflict of interest. The editors and reviewers of this article have no conflicts of interest.

Received for publication Nov 22, 2020; revisions received Nov 22, 2020; accepted for publication Nov 23, 2020; available ahead of print Jan 15, 2021.

Address for reprints: Vinod H. Thourani, MD, Department of Cardiovascular Surgery, Piedmont Heart Institute, 95 Collier Rd, Suite 5015, Atlanta, GA 30308 (E-mail: vinod.thourani@piedmont.org).

J Thorac Cardiovasc Surg 2021;161:1763-4

$0022-5223 / \$ 36.00$

Copyright (C) 2020 by The American Association for Thoracic Surgery

http://dx.doi.org/10.1016/j.jtcvs.2020.11.122
}

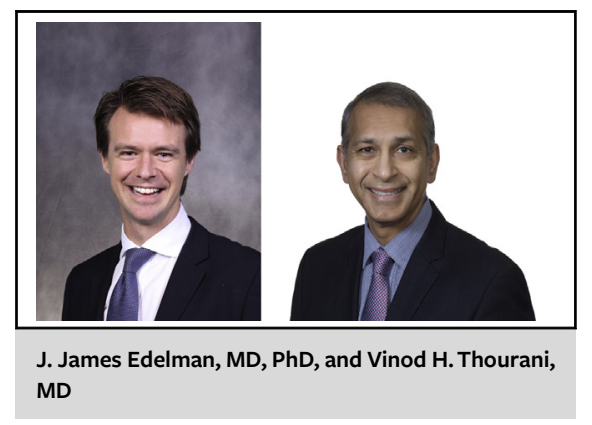

CENTRAL MESSAGE

TAVR is now a viable alternative to surgery as the standard treatment of aortic stenosis. Minimally invasive approaches to SAVR are essential for innovation to surgery.

using conventional techniques and a suture fastening device. The patient population was relatively low risk (Society of Thoracic Surgeons predicted risk of mortality $1.6 \%$ ), but did include patients with comorbidities such as severe lung disease, moderate-severe pulmonary hypertension, radiation valvulopathy with a calcified aortic root, and urgent cases. The duration of $\mathrm{CPB}$ and $\mathrm{XC}$ were long at 